\title{
BRASIL FRENTE À ESCASSEZ DE ÁGUA
}

Andréia de Menezes Olivo, Hamilton Mitsugu Ishiki

Universidade do Oeste Paulista - UNOESTE. Mestrado em Meio Ambiente e Desenvolvimento Regional, Presidente Prudente-SP. E-mail: andreiaolivo@unoeste.br

\section{RESUMO}

A água é uma fonte vital para o ser humano e sua escassez resulta do crescimento populacional rápido e desordenado, e acaba contribuindo para a redução da sua oferta, especialmente devido à poluição dos mananciais causadas pelo próprio homem. Pensando nisto, esta revisão tem como objetivo abordar o valor ambiental da água, às causas e consequências da sua escassez, bem como dos problemas que afetam a qualidade da água e por consequência a vida do homem. Pretende ainda expor os impactos de sua escassez e quais podem ser os reflexos da ação antropogênica e o descaso para com este bem. Para isto, foi realizada uma pesquisa bibliográfica descritiva e analítica da atual situação deste recurso no Brasil e no mundo, pautada em livros, artigos científicos e documentários, visando demonstrar a importância da água para o ecossistema, à problemática e os impactos de sua escassez para a sociedade.

Palavras-chave: Água; meio ambiente; reúso; qualidade; escassez.

\section{THE WATER SHORTAGE IN BRAZIL}

\begin{abstract}
The water is a vital resource to human and this shortage was resulted by rapid and unplanned population growth that contributes to reduce its offer, especially due to the water pollution caused by the human. Thinking about it, this revision have with objective discusses the water environmental value, the causes and consequences of its scarcity, as well as the problems that affect the water quality and consequently the man life. It also aims to expose the impacts of their scarcity and what might be the consequences of anthropogenic action and disregard for water. For this, was performad a research bibliographic descriptive and analytical in the current situation this resource in Brasil and the world, guided in books, scientific articles and documentaries, seeking to demonstrate the importance of water to the ecosystem, the problematic and the impacts of it scarcity for society.
\end{abstract}

Keywords: Water; environment; reuse; quality; shortage. 


\section{INTRODUÇÃO}

A água há milênios, é reconhecida como sendo uma substância vital que está presente na natureza, e é parte constituinte fundamental para a conservação dos ecossistemas e da vida de todos os seres em nosso planeta. A estrutura e as funções de um ambiente são determinantes para a sobrevivência de plantas, animais e demais seres vivos (WOLKMER, PIMMEL, 2013).

A água já foi considerada um recurso inesgotável; pois o ecossistema fazia crer que os mananciais de águas cristalinas, abundantes e renováveis nunca chegariam ao fim. Apesar de o planeta ser constituído superficialmente por aproximadamente $75 \%$ de água, existe o paradoxo da escassez, pois a água não está distribuída geograficamente de maneira uniforme (TUNDISI, 2003).

Alguns especialistas apontam que a crise da água está ocorrendo devido ao mau gerenciamento, entretanto para outros, a crise é decorrente de um conjunto de problemas ambientais agravados com outros problemas relacionados à economia e ao desenvolvimento social (TUNDISI, 2008).

A ação desregrada e inconsciente do homem está provando que a água é um bem esgotável e poderá acabar em breve. Tundisi (2003) acrescenta que existem atualmente cerca de 30 países que convivem com os problemas decorrentes da escassez de água, dentre os quais Kuwait, Emirados Árabes
Unidos, Ilhas Bahamas e a Faixa de Gaza, que compreende o território palestino, apresentam situação crítica (entre 10 a 66 $\mathrm{m}^{3}$ /ano/habitante).

O uso inconsciente dos recursos hídricos, a poluição de mananciais e a falta de chuva, estão fazendo com que o Sudeste do Brasil enfrente atualmente uma das suas piores crises com relação à falta de água e energia. Várias medidas emergenciais estão sendo providenciadas, porém a situação é alarmante (CORONATO, IMERCIO, 2014). O nível da água nos quatro sistemas de hidrelétricas no país caiu entre $18 \%$ a $57 \%$ se comparado com fevereiro de 2012.

A diminuição considerável das reservas de água limpa em todo o planeta, incluindo o Brasil, tem sido foco de preocupação dos especialistas e autoridades, considerando que a problemática é gerada principalmente em decorrência do mau uso, aliado á crescente demanda.

A percepção da escassez da água potável, para consumo humano, segundo Moraes e Jordão (2002), acarretada através do aumento da demanda, em consequência do crescimento demográfico e do desenvolvimento econômico, ou através da crescente deterioração da sua qualidade, causada principalmente através da poluição indiscriminada, tem levado os governos de todo o mundo a definirem novos direitos $\mathrm{e}$ obrigações. Através de um sistema de gestão 
participativo descentralizado, eles buscam a estimulação para que ocorra a utilização da água de forma racional.

Deste modo, é importante que toda a sociedade esteja consciente das maneiras adequadas de se utilizar os recursos hídricos disponíveis, a fim de causar os menores danos para a natureza. É importante que a sociedade esteja alerta para o uso sustentável deste bem comum, e que pressione os governantes para a estruturação de políticas capazes de fiscalizar a utilização correta, bem como o seu reuso, em nosso planeta.

Nesta perspectiva, o presente artigo tem como objetivo abordar a fundamental importância do elemento água para o meio ambiente e para o ser humano, e como os recursos hídricos estão sendo degradados e desperdiçados pelo homem. Pretende ainda expor os impactos que a sua escassez poderá provocar em todo o planeta, e quais serão os reflexos da ação antropogênica e o descaso para com este bem, sob a perspectiva econômica, política e social.

A metodologia consistiu em pesquisa bibliográfica, onde as fontes foram livros e artigos científicos que abordam a área do conhecimento denominada sociologia ambiental e ciência ambiental.

\section{A ATUAL SITUAÇÃO DOS RECURSOS HIDRICOS NO PLANETA}

Vários especialistas e estudiosos, ao redor do mundo, estão atentos à problemática da escassez da água, também denominada de "crise da água". O estresse e a escassez da água podem estar mais próximos do que a humanidade possa imaginar. De acordo com Spiro e Stigliani (2009), os reservatórios de água demonstram sua insuficiência acentuada. Nos períodos de longas estiagens as reservas hídricas estão se exaurindo muito mais rapidamente do que podem ser reabastecidos, devido aos problemas principalmente de contexto social, econômico e ambiental.

Tundisi (2003) nos coloca a par de que, em muitos locais, a escassez da água de boa qualidade está fazendo com que haja a necessidade de se transportar a água por longas distâncias, e com o emprego de técnicas de elevado custo. Esses custos elevados representam um impacto às economias que enfrentam dificuldades na obtenção desse bem tão necessário à todas as sociedades do mundo.

Para muitos países a escassez de água poderá ser um fator determinante para o próprio desenvolvimento, pois aqueles que insistirem em manter o modelo tecnológico baseado apenas na exploração dos recursos naturais, enfrentará problemas de ordem econômica, política e social. Muitos países 
podem entrar em guerra devido à carência de seus recursos hídricos, pois vários estudos indicam que o consumo mundial de água dobra a cada 20 anos (CAUBET, 2006).

A água passa a ser considerado um recurso de elevado valor social, econômico e principalmente ecológico, pois as taxas de consumo e o crescimento da população se elevam em razão geométrica de aproximadamente $1,6 \%$ ao ano. De acordo com a elevação destes índices, o esgotamento do potencial hídrico ocorrerá por volta do ano 2053 (REBOUÇAS, 2003).

Atualmente, alguns países do continente africano e no Oriente Médio já enfrentam a escassez crônica de água. Países como México, Hungria, Índia, China, Tailândia e Estados Unidos já apresentam limites críticos na quantidade de recursos hídricos. Situação esta causada por inúmeros fatores como excedente populacional nestas regiões, o desperdício por falta de conscientização e o descaso pelo baixo valor monetário que ainda paga-se pela água (UNIAGUA, 2012).

A distribuição dos potenciais de água doce não ocorre de modo uniforme. A desigualdade na distribuição dos recursos hídricos acaba contrastando com as diferenças populacionais. Um dos exemplos ocorre na Ásia, que possuí o continente mais populoso com cerca de $60 \%$ dos habitantes, e possuí apenas $31 \%$ da disponibilidade da água doce superficial terrestre. Por outro lado, as Américas que possuem apenas 13,6\% da população mundial possuem $41 \%$ de toda a água disponível (REBOUÇAS, 2006; AUGUSTO, 2012).

Ao se avaliar a atual situação de desperdício e escassez de água pode-se concluir que exista uma demanda crescente por água doce subterrânea, o que está levando a um esgotamento rápido e alarmante dos aquíferos. Existem alguns fatores que contribuem diretamente para este esgotamento, como por exemplo, os ineficientes processos de irrigação que colaboram para o desperdício da água de boa qualidade, o desordenado e elevado crescimento da população, principalmente em regiões áridas que são mais pobres e menos desenvolvidas e o consumo exagerado do setor industrial.

Leme (2008) enfatiza que a disponibilidade da água é um dos principais fatores que determinam a ocupação geográfica, o controle habitacional e o desenvolvimento regional. Tundisi (2003) também enquadra que a aceleração da economia e o seu desenvolvimento, a diversificação da sociedade, o aumento populacional e o desenvolvimento cultural acabam contribuindo diretamente para que outras necessidades sejam incorporadas em relação ao uso dos recursos hídricos. Como resultado, ocorre o aumento dos impactos e na variedade de contaminação das águas 
subterrâneas e das reservas ainda disponíveis.

\section{A FALTA DE ÁGUA NO BRASIL PASSOU DE FUTURO PARA PRESENTE}

Até pouco tempo atrás era considerado pessimista aquele que discursava sobre a possível falta de água que a sociedade brasileira poderia enfrentar, pois bem este dia chegou. A abundância que sempre deixou a população e governantes com uma falsa sensação de segurança demonstram que a escassez de água é real e atual.

O Brasil é o maior depositário natural de águas doces do planeta. Segundo dados do UNIAGUA (2012), o Brasil detém 11,6\% de toda a água doce superficial do mundo, sendo que $70 \%$ da água disponível está localizada na região Amazônica, onde se encontra a menor densidade populacional. A região Nordeste, que é a mais pobre e também a mais árida, concentra $30 \%$ da população brasileira e possuí apenas 5\% da água doce. As regiões Sul e Sudeste, onde estão concentradas cerca de $60 \%$ da população dispõem de $12,5 \%$ da água doce (AUGUSTO et al., 2012).

Atualmente, a área de captação de água do Sistema Cantareira que pertence à cidade de São Paulo, na região sudeste do Brasil, enfrenta a maior estiagem desde que começaram as medições, em 1930. Esta situação ocasionou a redução do volume das lagoas abaixo de $15 \%$ do limite máximo, tornando necessário a utilização do volume morto deste sistema de abastecimento para suprir a demanda da população da Cidade de São Paulo (CORONATO, IMERCIO, 2014).

Mesmo frente a todas estas constatações da escassez de água que a sociedade tende a enfrentar, 0 seu desperdício atinge níveis nunca imaginados. De acordo com Rebouças (2003) os índices de perdas totais da água tratada e injetada nas redes de distribuição das cidades do Brasil variam entre $40 \%$ a $60 \%$, sendo que nos países desenvolvidos estes valores se encontram em patamares de $5 \%$ a $15 \%$. Adicionalmente, o que também preocupa é o descaso do drama sanitário nas cidades brasileiras que sofrem sem a merecida atenção das autoridades - Executivo, Legislativo e Judiciário. Aliás, o descaso dos governantes não ocorre apenas no Brasil (CASTRO, 2007).

Existem no País graves problemas sociais relacionados com a água, que vai desde situações de carência absoluta até o desperdício franco; passando por problemas de baixa qualidade por contaminação orgânica e química, falta de consciência para o reuso, entre outras (AUGUSTO, 2012).

A questão do desperdício da água sempre esteve associada a uma questão cultural da sociedade, a da falsa ideia de que 
a água é um recurso natural infinito. A população desperdiça água em seus domicílios, as indústrias e a agricultura, todas juntas usam de maneira inconsciente a água para fins que não exigem água potável.

Segundo pesquisas realizadas pela Agência Nacional de Águas indicam que somente a agricultura é responsável por aproximadamente $70 \%$ do consumo de toda a água no Brasil, e também é recordista de desperdício na irrigação. É na agricultura que se concentra um dos maiores agravantes na ordem de desperdício de água tanto no Brasil quanto no mundo. Os projetos de irrigação no mundo perdem quantidades significativas de água potável, e se houvesse a redução de apenas $10 \%$ de toda a água utilizada na agricultura já seria suficiente para abastecer o dobro da população existente hoje no mundo, cerca de 7,0 bilhões de pessoas (REBOUÇAS, 2003).

A indústria consome $7 \%$ da água e desperdiça menos, mas há anos paga pelo volume de água que capta, e finalmente a população é responsável por $10 \%$ do desperdício. As maiores perdas estão associadas à manutenção deficiente das tubulações, e a inadequada gestão comercial das companhias de saneamento (TSUTIYA, 2005).

Considerando o consumo da população, a perda no faturamento dos sistemas de abastecimento de água varia entre $27 \%$ a $60 \%$. Estas perdas podem ser divididas em físicas, geradas por vazamentos desde a captação da água até a sua distribuição e perdas não físicas, geradas por ligações clandestinas, defeitos em hidrômetros, fraudes, dentre outras (SALOMANI, DELLA, BACK, 2014).

Desta forma, é fundamental e urgente a promoção de vários estudos sobre os recursos hídricos e as suas aplicações a fim de promover visões e cenários de longo prazo, que possam estimular o correto gerenciamento e a recuperação deste bem valioso.

\section{CONSIDERAÇÕES FINAIS}

O desafio deste trabalho foi abordar de maneira crítica e destacar as principais questões que fazem parte da atual situação que se encontra a problemática da água no Brasil e no mundo. A água é um bem essencial à vida e tem sua importância no desenvolvimento econômico, no bem estar social e necessita de uma gestão e legislações especiais, pois possui características singulares.

Os temas aqui abordados apresentam uma dimensão da visão dos autores, na busca de descrever a realidade dos problemas que cercam a sociedade no futuro em relação à importância do recurso água, a sua qualidade, para garantir maior produtividade sem exaurir as reservas naturais, expor de 
maneira direta os que sua escassez pode vir a causar para a sociedade vêm fazendo para conter o avanço desta futura crise e qual a posição da sociedade e de que forma ela pode mudar o desfecho desta realidade.

\section{REFERÊNCIAS}

AUGUSTO, L. G. S.; GURGEL, D. G. I.; CÂMARA NETO, F. H.; MELO, H. C.; COSTA, M. A. O contexto global e nacional frente aos desafios do acesso adequado à água para consumo humano. Revista Ciência e saúde coletiva, Rio de Janeiro, v. 17, n. 6, Jun. 2012. Disponível

em:<http://www.scielo.br/scielo.php?script= sci_arttext\&pid

=S141381232012000600015\&lng=en\&nrm=is o>. Acesso em: 22 jul. 2014.

CASTRO, J. E. Water governance in the twentieth-first century. Revista Ambiente e Sociedade, Campinas, v. 10, n. 2, Dez. 2007. Disponível em: <http://www.scielo.br/ scielo.php?script=sci_arttext \&pid=S1414753 X2007000200007\&lng=en\&nrm=iso>. Acesso em : 22 Jul. 2014.

CAUBET, C. G. A Água Doce nas Relações Internacionais. Barueri, SP: Manole, 2006.

CORONATO, M.; IMERCIO, A. O Brasil pede água. Revista Época, São Paulo, v. 3, n 825, p.44-50, março 2014.

LEME, A. J. E. Manual prático de tratamento de águas residuárias. 1a $\mathrm{Ed}$. São Carlos: UFSCAR, 2008.

MORAES, L. S. D; JORDÃO, Q. B. Water resources deterioration and its impact on human health. Revista Saúde Pública, São Paulo, v. 36, no 3, p.370/374, 2002.

REBOUÇAS, C. A. Água no Brasil: abundância, desperdício e escassez. Revista Bahia Análise
\& Dados, Salvador, v.13, no especial, p. 341345, 2003.

REBOUÇAS, C. A. Águas Doces no Mundo e no Brasil. In: REBOUÇAS, C. A.; BRAGA, B.; TUNDISI, G.J. Águas Doces no Brasil: capital ecológico, uso e conservação. 3a Ed. São Paulo: Escrituras Editora, v.1, cap. 01, 2006.

SALAMONI, S. S.; DELLA, P. J.; BACK, J. A. Avaliação das perdas na distribuição das perdas na distribuição de água: Estudo de caso em São Bento baixo, Nova Veneza-SC. Revista Tecnologia e Ambiente, Criciúma, v. 20, junho, 2014. Disponível em: http://periodicos.unesc.net/index.php/tecno ambiente/article/viewFile/1563/1479.

Acesso em: 20 jul. 2014.

SPIRO, T. G, STIGLIANI, W. M. Química Ambiental. 2a . Ed. São Paulo: Pearson Prentice Hall, 2008-2009.

TSUTIYA, M. T. Abastecimento de água. 2a Ed. São Paulo: Departamento de Engenharia Hidráulica e Sanitária da Escola Politécnica da Universidade de São Paulo, 2005.

TUNDISI, J. G. Recursos Hídricos. Instituto Internacional de Ecologia, São Carlos, 2003. Disponível em http://www.multiciencia.unicamp.br/artigos _01/A3_Tundisi_port.PDF. Acesso em: 30 jun. 2012.

TUNDISI, J. G. Recursos hídricos no futuro: problemas e soluções. Revista Estudos Avançados, São Paulo, v. 22, n. 63, julho, 2008. Disponível em: $<$ http://dx.doi.org/10.1590/ S010340142008000200002. Acesso em: 22 jul. 2014.

UNIÁGUA - Universidade da Água. Água no Planeta. Disponível em: $<$ www.uniagua.org.br/aguaplaneta.htm $>$. Acesso em: 07 jun. 2012. 
WOLKMER, M. F. S.; PIMMEL, N. F. Política nacional de recursos hídricos: governança água e cidadania ambiental. Revista Sequência, Florianópolis, v. 34, n. 67, Dez. $2013 . \quad$ Disponível em: <http://www.scielo.br/scielo.php?script=sci_ arttext\&pid=S2177-

70552013000200007\&lng=en\&nrm=iso $>$. Acesso em: 22 jul. 2014.

Recebido para publicação em 05/08/2014

Revisado em 25/08/2014

Aceito em 01/09/2014 